УДК $550.389+504.06$

\title{
МАГНИТНЫЕ АНОМАЛИИ НА ПЛОЩАДКЕ ОБЪЕКТА МИРНОГО ПОДЗЕМНОГО ЯДЕРНОГО ВЗРЫВА «КРИСТАЛЛ» (ЗАПАДНАЯ ЯКУТИЯ)
}

\author{
Артамонова Светлана Юрьевна 1 , \\ artam@igm.nsc.ru
}

\author{
Шеин Александр Николаевич2,3,4, \\ SheinAN@ipgg.sbras.ru
}

Потапов Владимир Владимирович2,4, PotapovVV@ipgg.sbras.ru

\author{
Кожевников Николай Олегович², \\ KozhevnikovNO@ipgg.sbras.ru
}

\author{
Новикова Полина Николаевна 5 , \\ polinagfz@gmail.com
}

Ушницкий Владислав Егоровичб,

1 Институт геологии и минералогии им. В.С. Соболева СО РАН, Россия, 630090, г. Новосибирск, пр. Академика Коптюга, 3.

2 Институт нефтегазовой геологии и геофизики им. А.А. Трофиимука СО РАН, Россия, 630090, г. Новосибирск, пр. Академика Коптюга, 3.

3 Научный центр изучения Арктики, Россия, 629008, г. Салехард, ул. Республики, 20.

4 Забайкальский государственноый университет, Россия, 672039, Россия, г. Чита, ул. Александро-Заводская, 30.

5 Горный институт УрО РАН, Россия, 614007, г. Пермь, Сибирская, 78а.

${ }^{6}$ Министерство экологии, природопользования и лесного хозяйства РС (Я), Россия, 677000, Якутск, ул. Дзержинского, 3/1.

\begin{abstract}
Актуальность исследования обусловлена необходимостью оценки текущей радиационной и геоэкологической обстановки и прогнозирования возможных сценариев развития на объектах мирных подземных ядерных взрывов, в первую очередь, расположенных вблизи населенных пунктов. Детализация строения геотехногенной системы «центр подземного ядерного взрыва - вмещающая геологическая среда - поверхность Земли» предусматривает проведение магнитных исследований, которые позволяют отделить геоэлектрические аномалии, вызванные погребенными железными объектами, от остальных, имеющих другую природу.

Цель: обнаружение и локализация погребенных железных объектов на объекте мирного подземного ядерного взрыва «Кристалл» по результатам наземной магнитной съемки.

Объектом исследования выбрана площадка боевой скважины мирного подземного ядерного взрыва «Кристалл», произведенного 2 октября 1974 г. на глубине 98 м в мерзлых породах в 6,7 км от г. Удачный (Западная Якутия). Мощность взрыва составила 1,7 кт в тротиловом эквиваленте. В 1992 г. устье боевой скважины было засыпано обломочным материалом, в 2007 г. проведена дополнительная досыпка. Диаметр насыпи (или саркофрага) - около 260 м, высота - до 20 м.

Mетоды: наземная магнитная съемка протонным магнитометром MMPOS-1 с частотой отсчета 3 c, с геопривязкой точек с помощью GPS приёмника. Вариации магнитного поля регистрировались квантовым магнитометром GSM-19 с частотой 10 с в лесном участке около площадки объекта «Кристалл». При анализе данных использованы программные комплексы статистического и спектрально-корреляционного анализа геоданных «КОСКАД ЗD» (авторы А.А. Никитин, А.В. Петров, А.С. Алексашин) и численного моделирования PRIZMA (автор А.С. Долгаль).

Результаты. На основе базы данных из 5323-х точек измерения магнитного поля на площадке боевой скважины мирного подземного ядерного взрыва «Кристалл» размером 430×330 м построена карта аномального магнитного поля $\triangle T$ Т. Выявлены магнитные аномалии разной интенсивности и размеров, источником которых являются погребенные железные объекты. Наиболее широкую и интенсивную аномалию диаметром в 46 м и амплитудой до 8000 нТл, расположенную над устьем боевой скважины, путем последовательной энергетической фильтрации удалось разложить на составляющие и соотнести их $c$ фррагментами конструкции боевой скважины. Расчетные модели магнитных аномалий, фрормируемых вертикальным и субгоризонтальным фрагментами обсадной колонны боевой скважины, оказались близки к измеренным данным, тем самым подтвержден аддитивный характер магнитной аномалии над устьем боевой скважины. Остальные магнитные аномалии предположительно обусловлены фрагментами обсадных труб исследовательских буровых скважин, существовавших до взрыва на площадке, и технических труб, использованных при строительстве боевой скважины, хаотично перемещенных при взрыве.
\end{abstract}

\section{Ключевые слова:}

Наземная магнитная съемка, геоэкологические исследования, мирный подземный ядерный взрыв, Якутия.

\section{Введение}

С 1965 по 1988 гг. в рамках государственной программы СССР № 7 «Ядерные взрывы для народного хозяйства» было проведено 124 мирных подземных ядерных взрыва (ПЯВ) общей мощностью 1783,7 кт в тротиловом эквиваленте [1]. Подобные эксперименты проводились в США, Франции и других странах. 
В России объекты ПЯВ стали доступны для научной общественности после их рассекречивания в 1990-ые гг. В других странах, судя по росту публикационной активности, их широкое изучение началось в то же время. На [2] по ключевому слову «Underground nuclear explosion» за 1977-2019 гг. найдено всего 566 публикаций. До 1991 г. публиковалось в среднем по три работы в год, затем наблюдается резкий рост: в 1991-2012 гг. в среднем выходило по 15 работ в год, с 2013 г. - уже по 27 работ. Почти половина из 566 публикаций посвящена методикам распознавания ядерных испытаний: к ним можно отнести 248 работ, выделенных из выборки по ключевому слову «seismic», и 30 работ, выделенных по ключевому слову «gas transport», об изотопах благородных газов индикаторах ПЯВ в атмосфере (таблица). Примерно четверть работ из оставшихся связана с радиогеохимическим изучением районов ПЯВ. Таким образом, объекты ПЯВ, как геотехногенные системы, рассматриваются в 200-х работах. Среди них по ключевому слову «TEM data» найдено две статьи, посвященные результатам зондирования становлением поля в ближней зоне (ЗСБ) в 2008 г. на объектах ПЯВ «Кристалл» [3] и «Кратон-3» [4], выполненных сотрудниками ИГМ СО РАН и ИНГГ СО РАН. По ключевому слову «Geomagnetic» из выборки выделено четыре работы, посвященные оценке возмущения геомагнитного поля при ПЯВ. Публикаций по наземной или иной магнитной съемке объектов ПЯВ в корневой коллекции Web of Science [2] не найдено, и в этой области наши работы оказались пионерными. Это тем более неожиданно, потому что магнитная съемка успешно используется при поисках, распознавании и картировании подземных техногенных коммуникаций и объектов [5-10].

В России основное внимание исследователей уделялось радиационному воздействию ПЯВ на поверхностные ландшафты, радиоактивному загрязнению почв, растений, водоемов [11-13]. Хотя некоторые исследователи изучали эффекты воздействия ПЯВ на геологическую среду [14-16], состояние недр большинства ПЯВ остается недостаточно изученным или вовсе неизученным.

Таблица. Анализ публикационной активности в области изучения ПЯВ в 1977-2019 г2. по данHolм [2]

Table. $\quad$ Analysis of publication activity of peaceful underground nuclear explosion (PUNE) study in $1977-2019$ by [2]

\begin{tabular}{|c|c|c|c|}
\hline \multirow{2}{*}{ 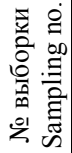 } & \multicolumn{2}{|c|}{$\begin{array}{c}\text { ключевое слово } \\
\text { key word }\end{array}$} & \multirow{2}{*}{$\begin{array}{c}\text { Число } \\
\text { публикаций } \\
\text { Quantity } \\
\text { of publications }\end{array}$} \\
\hline & $\begin{array}{l}\text { Первое } \\
\text { first }\end{array}$ & $\begin{array}{c}\text { второе (уточняющее) } \\
\text { second (clarifying) }\end{array}$ & \\
\hline 1 & \multirow{10}{*}{$\begin{array}{l}\text { under- } \\
\text { ground nu- } \\
\text { clear } \\
\text { explosion }\end{array}$} & - & 566 \\
\hline 2 & & seismic & 248 \\
\hline 3 & & gas transport & 30 \\
\hline 4 & & $\mathrm{U}, \mathrm{Pu},{ }^{137} \mathrm{Cs},{ }^{3} \mathrm{H}$ & $\sim 33$ \\
\hline 5 & & water migration & 42 \\
\hline 6 & & aquifer & $6(3 *)$ \\
\hline 7 & & geological & 33 \\
\hline 8 & & geophysical & 21 \\
\hline 9 & & TEM data & $2 *$ \\
\hline 10 & & geomagnetic & 4 \\
\hline
\end{tabular}

* соавторы: Кожевников Н.О., Артамонова С.Ю.

* coauthors: Kozhevnikov N., Artamonova S.

Итак, небольшое количество публикаций по данной проблеме едва ли можно объяснить недостатком интереса к объектам ПЯВ. Возможно, до сих пор существуют ограничения для их широкого изучения. Такую ситуацию нельзя признать удовлетворительной, особенно с учетом того, что комплексное геоэкологическое изучение объектов ПЯВ может дать важную информацию для решения не менее важной проблемы захоронения радиоактивных отходов.

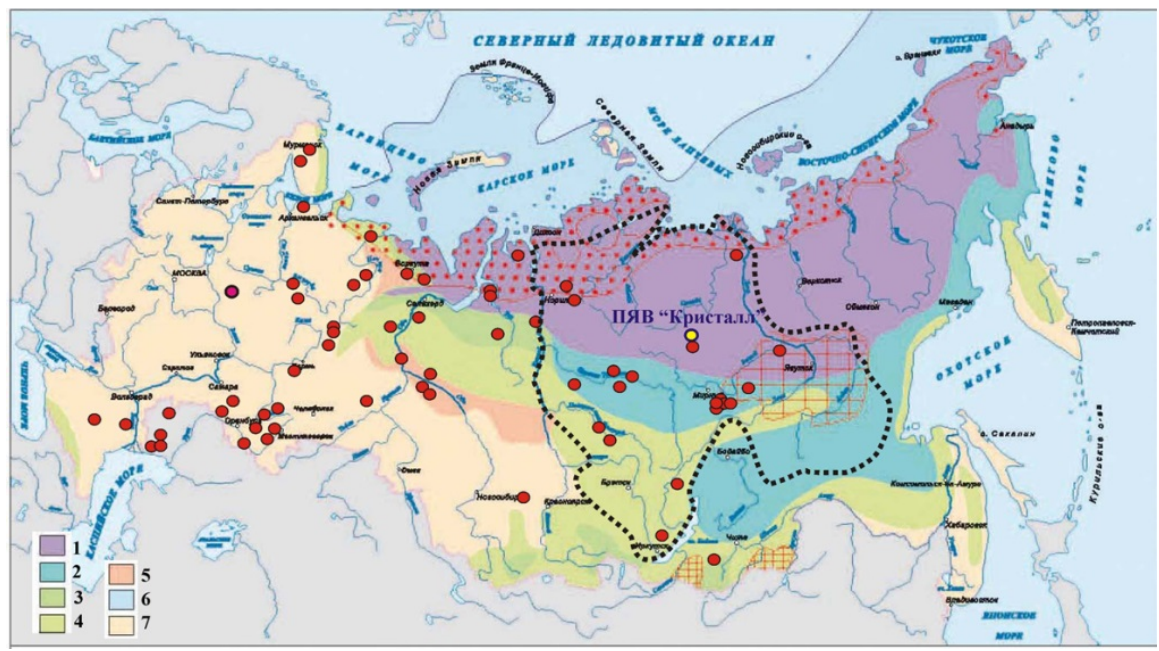

Рис. 1. Расположение объекта «Кристалл» (желтый кружок) и остальных ПЯВ на территории России (красные кружки). Условные обозначения распространения многолетней мерзлоты: 1 - сплошное, 2 - прерывистое, 3 -массивно-островное, 4 -островное и редкоостровное, 5 - реликтовое, 6 - мерзлота на шельфе, 7 - отсутствие многолетней мерзлоты; шттиховой линией показан контур Сибирской платформы

Fig. 1. Sites of the PUNE in Russia (red marks) and the "Crystal» object (yellow mark). Legend of permafrost degree: 1 continuous, 2 -sporadic, 3 -massive-insular, 4 -insular and rare insular, 5 -relict, 6 -shelf, 7 -non-frozen rocks; black dash-line - the contour of the Siberian platform 
На территории России 51 из 85 ПЯВ были проведены в зоне многолетней мерзлоты, чувствительной к воздействию внешних факторов (рис. 1). Актуально изучение объектов ПЯВ, расположенных вблизи населенных пунктов, в районах интенсивной горнодобывающей деятельности. Для прогнозирования возможных сценариев развития геотехногенной системы «центр ПЯВ - вмещающая геологическая среда - поверхность Земли» необходимо проведение исследований с применением комплекса дистанционных методов. В условиях контрастной геоэлектрической среды криолитозоны для изучения объектов ПЯВ эффективно применение методов электроразведки. Для разделения геоэлектрических аномалий, вызванных погребенными железными объектами, и геоэлектрических аномалий, имеющих другую природу, электроразведочные исследования следует дополнять магнитной съемкой.

Целью наших исследований, результаты которых представлены в настоящей статье, было обнаружение и локализация погребенных железных объектов на объекте ПЯВ «Кристалл» по результатам наземной магнитной съемки.

Интенсивное развитие алмазодобычи и расположение поблизости г. Удачный делают изучение недр, где был проведен ПЯВ «Кристалл», особенно актуальным, что предопределило его выбор в качестве эталонного.

\section{Краткая характеристика объекта ПЯВ «Кристалл»}

ПЯВ «Кристалл» мощностью 1,7 кт в тротиловом эквиваленте был произведен 02.10.1974 г. на глубине 98 м в мерзлых породах левого борта ручья УлаханБысыттах в 6,7 км от г. Удачный (Западная Якутия). Это был единственный в СССР ПЯВ на рыхление и в этом отношении является уникальным. Для создания навалов общей длиной 1800 м, шириной по гребню 85 м, высотой 27-30 м, как основы для плотины хвостохранилища, планировалось по линейному ряду поперек долины ручья Улахан-Бысыттах провести еще семь таких же взрывов. Однако навал ПЯВ «Кристалл» оказался высотой не более 14 м, т. е. гораздо ниже расчетной, что послужило официальной причиной для отказа от проведения остальных взрывов.

При строительстве боевой скважины ПЯВ «Кристалл» в ствол на глубину до 6 м было установлено шахтное направление из трубы длиной 6 м, диаметром в 142 см, толщиной металла в 12 мм. В него вкладывалась обсадная колонна диаметром 122 см, толщиной металла в 12 мм, состоящая из труб, соединенных высокотемпературной сваркой, на глубину до 38 м. Судя по параметрам, трубы соответствовали ГОСТ 10706-63 СССР: погонная масса трубы с диаметром 122 см составляла 357,5 кг/м, с диаметром 142 см - все 416,7 кг/м. Большой диаметр боевой скважины и обсадной колонны, по-видимому, был обусловлен размером взрывного устройства.

При взрыве верхняя часть обсадной колонны длиной 12 м оторвалась и была выброшена на поверхность навала. Этот фрагмент обсадной колонны, лежащий субгоризонтально, был сфотографирован во время посещения объекта правительственной комиссией Рес- публики Саха (Якутия) в 1990 г. [17] (рис. 2, а). На заднем плане видны отвалы карьера кимберлитовой трубки «Удачная», т. е. объектив фотоаппарата был направлен на юго-запад, следовательно, фрагмент обсадной колонны, как можем судить, был ориентирован приблизительно по широте - на северо-западо-запад (рис. 2, б). В архивных документах данные о выходе на поверхность еще какого-либо другого фрагмента конструкции боевой скважины, кроме как о двенадцатиметровом фрагменте обсадной колонны, не приводятся.

В 1992 г. навал, образованный взрывом, был засыпан обломочным материалом; в 2007 г. была проведена дополнительная досыпка, в результате образовалась насыпь (саркофаг) диаметром 260 м, высотой до 20 м.

Район расположен в Якутской алмазоносной провинции на Сибирской платформе (рис. 1). Геологический разрез на глубину до 2200 м сложен известняками, доломитами и их глинистыми разностями. Верхний слой мощностью 150-200 м находится в многолетнемерзлом состоянии. Ниже располагаются три подземных водоносных горизонта, насыщенные напорными высокоминерализованными рассолами. В 2008 г. установлено вытекание из-под саркофага ПЯВ «Кристалл» солоноватых вод, содержащих хлориды и техногенные радионуклиды [18]. Впервые проведенные зондирования методом ЗСБ выявили локальную геоэлектрическую аномалию под эпицентром взрыва, которая в 2008 г. была объяснена подъёмом подземных рассолов по ослабленной взрывом зоне [3]. При интерпретации данных ЗСБ не были учтены погребенные под насыпью железные объекты, например обсадная колонна боевой скважины. В связи с этим в 2019 г. нами проведена наземная магнитная съёмка с целью поисков и оконтуривания железных объектов, учет которых необходим для построения геоэлектрической модели современного состояния недр, где в 1974 г. был проведен ПЯВ «Кристалл».

\section{Экспериментальная часть: методика полевых измерений}

Площадка боевой скважины ПЯВ «Кристалл» размером $430 \times 330$ м окружена забором из вкопанных металлических труб высотой до 2,5 м, соединенных металлической проволокой. На площадке были разбиты 30 профилей длиной 380 м (рис. 3) примерно с 10-метровым отступом от забора для предотвращения помех от него. Расстояние между профилями составляло 10 м. Измерения модуля полного вектора геомагнитного поля выполнены с помощью протонного магнитометра MMPOS-1, основанного на эффекте Оверхаузера (производство УГТУ-УПИ, Россия, Екатеринбург). Магнитная съемка осуществлялась путем равномерного перемещения по профилям, при этом оператор следовал за работником, задающим направление по приёмнику GPS (Garmin64st). Интервал между измерениями составлял 3 секунды, что соответствовал расстоянию примерно 2 м. Координаты каждой точки записывались GPS приёмником. Выполнено 5051 измерений при суммарной длине профилей около 11400 м. Проведено 288 контрольных замеров по двум профилям. Абсолютная погрешность измерений магнитометром MMPOS-1 составила 1 нТл. 

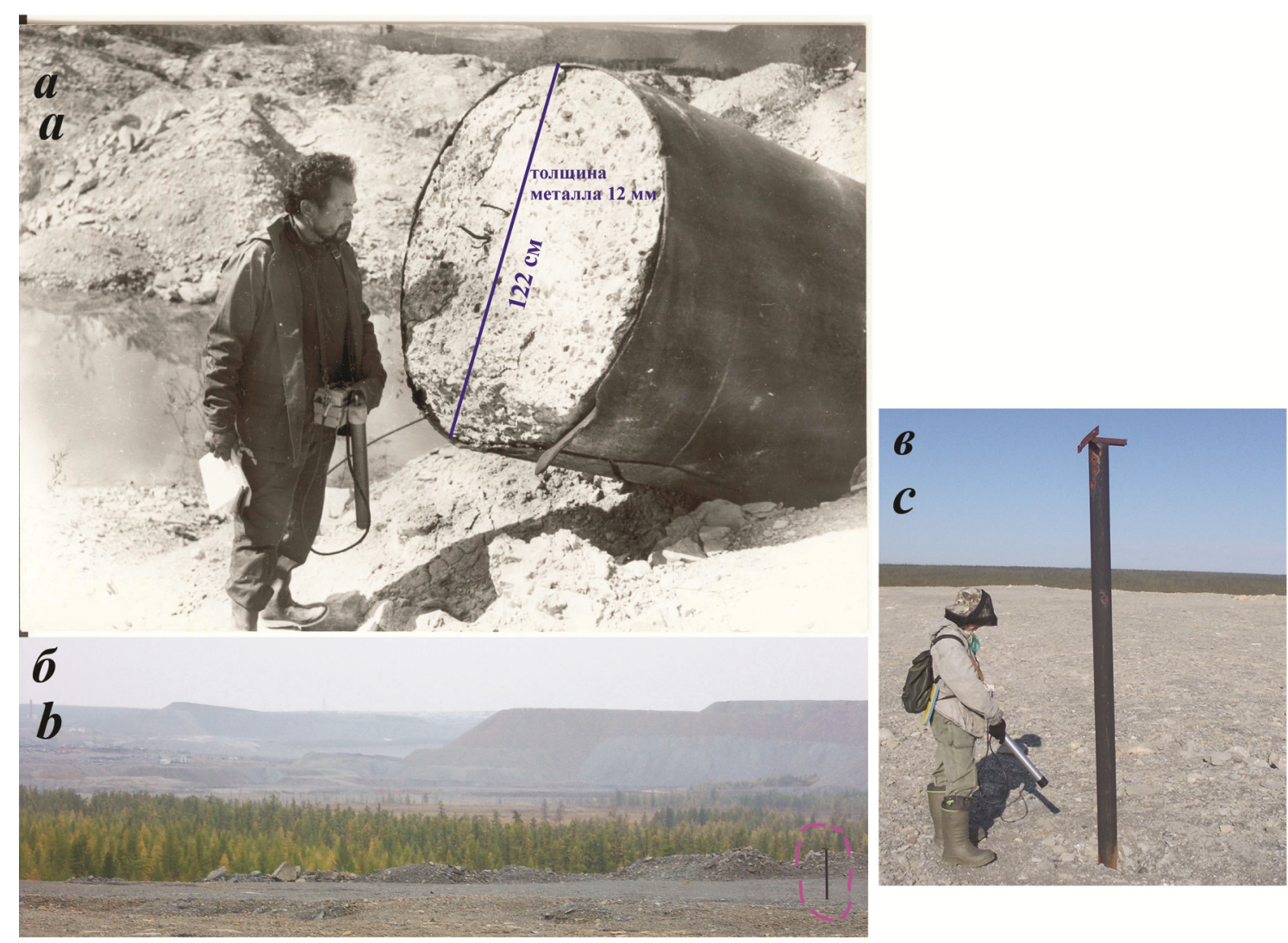

Pис. 2. а) фрагмент обсадной колонны с цементной пробкой длиной в 12 м, выброшенный взрывом на объекте «Кристалл» (фото И.Д. Архипова, с радиометром Е.С. Секов, 1990 г.) [17. С. 32]; б) вид с северо-восточной стороны насыпи ПЯВ «Кристалл» на отваль карьера кимберлитовой трубки «Удачная» в 2019 г., столб-репер, установленный над устьем боевой скважины, обведен пурпурным шттихом; в) столб-репер (объектив направлен на север), рост человека $155 \mathrm{~cm}$

Fig. 2. a) cement-filled casing fragment of the emplacement hole of the "Crystal» (12 $\mathrm{m}$ long) (depicted by I.D. Arkhipov, E.S. Sekov with the radiometer is on the photo, 1990) [17. P. 32]; b) rock heaps of the kimberlite pipe "Udachnaya», view from the northern-east side of the "Crystal» PUNE mound in 2019, the benchmark of the emplacement hole contoured by purple dash-line; c) benchmark (view to north), human height is $155 \mathrm{~cm}$

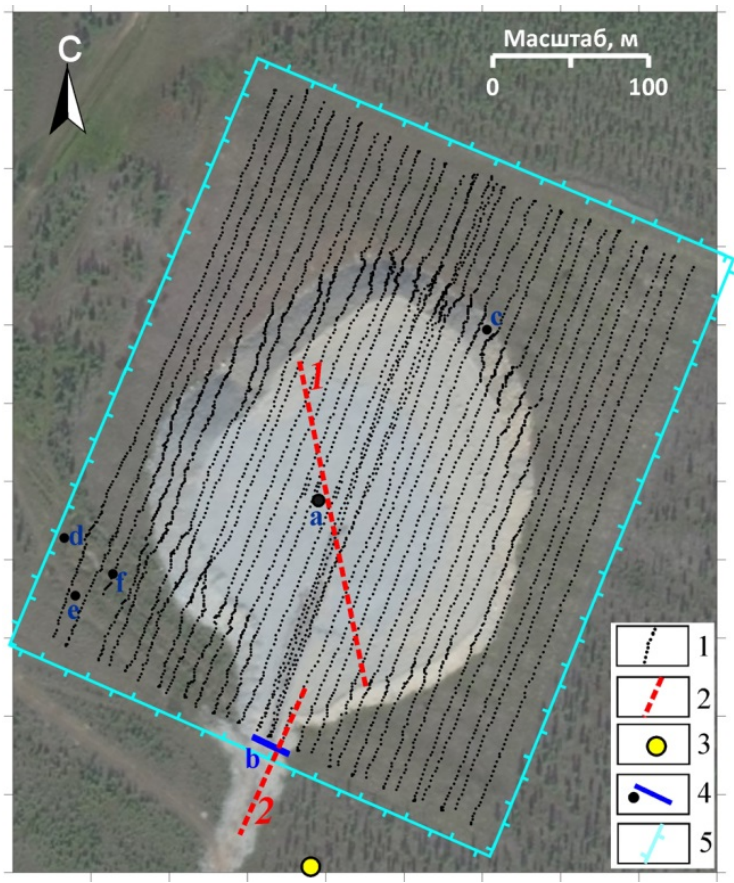

Для детализации параметров выявленных магнитных аномалий проведены дополнительные замеры по двум профилям (рис. 3,4$): 1)$ через центр саркофага с магнитного севера на юг длиной в 220 м с шагом между замерами 1 м; 2) в поперечном направлении через забор и две трубы, проложенные на поверхности Земли вдоль забора и присыпанные сверху рыхлым материалом дорожной насыпи толщиной около 1 м, с получением 53 дискретных данных.

Puc. 3. Схема наземной магнитной съемки на площадке объекта ПЯВ «Кристалл». Условные обозначения: 1 - треки замеров; 2 - детализаиионные профили № 1, 2; 3 -магнитовариационная станция; 4 -железные объекты на поверхности: а) столб-репер над устьем боевой скважины; b) две трубы под насыпью дороги для переброски склоновых стоков; c) чина от карьерного грузовика БЕЛАЗ; d) бочки; е) лист; f) проволока; 5 - забор вокруг площадки

Fig. 3. Land geomagnetic survey on the site of the PUNE «Crystal». Legend: 1 - measuring tracks; 2 - clarifying profiles no. 1, 2; 3 -geomagnetic variation station; 4 -iron objects on the land surface: a) benchmark; b) two water run-off tubs under the roadbed; c) car-tire of BELAZ truckful; d) barrels; e) sheet; f) wire; 5) paling of the site 


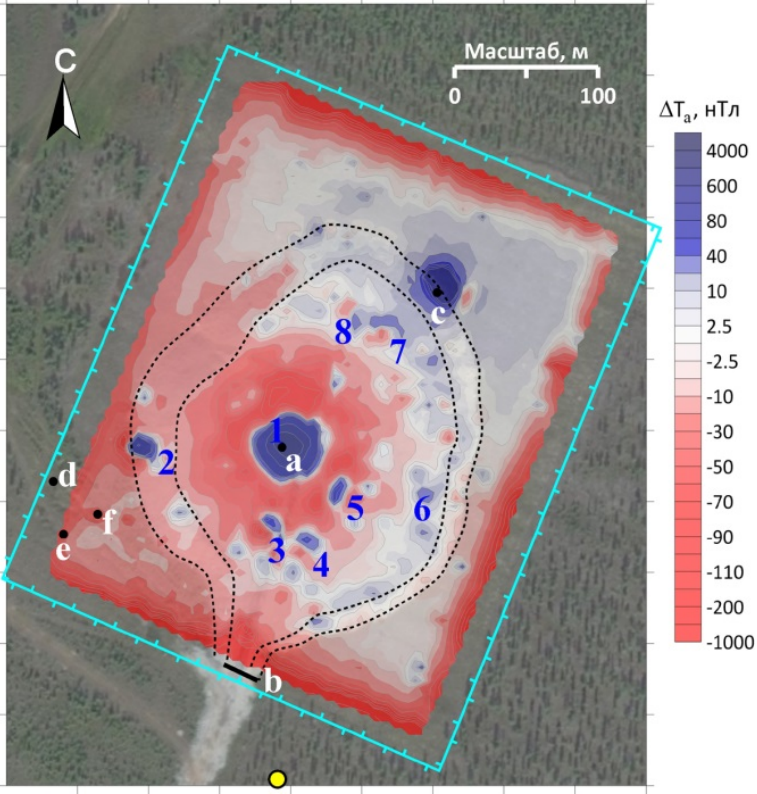

Pис. 4. Карта аномального магнитного поля на площадке ПЯВ «Кристалл» (нТл). Крупные и интенсивные магнитные аномалии пронумерованы (№ 1-8). Условные обозначения (a-f) железных объектов на поверхности площадки см. рис. 3. Штриховой линией показан контур насыпного саркофага (подножье и кромка верхней поверхности саркофага)

Fig. 4. Map of the anomalous geomagnetic field on the site of the PUNE "Crystal» (nTl). Wide and intensive anomalies numbered (no. 1-8). Legend of surface iron object $(a-f)$ see Fig. 3. The PUNE "Crystal» mound contoured by dash-line (bottom and upper edge)

Учет вариации магнитного поля проводился на лесном участке около площадки «Кристалл» квантовым магнитометром GSM-19 (производство Gem System, Канада) с частотой 10 с (рис. 3). Абсолютная погрешность измерений прибора составила 0,1 нТл.

\section{Методика обработки и интерпретации данных}

Полевые данные наземной магнитной съемки площадки ПЯВ «Кристалл» систематизированы и собраны в базу данных, которая стала основой для подготовки статьи. При обработке данных использована программа Microsoft Office Excel 2007, для визуализации - Golden Software Surfer. Для анализа данных привлекался комплекс статистического и спектрально-корреляционного анализа геоданных «КОСКАД 3D» (авторы А.A. Никитин, А.B. Петров, A.С. Алексашин) [19]. С использованием программного комплекса PRIZMA (автор А.С. Долгаль) [20] в первом приближении получены численные модели магнитных аномалий, формируемые вертикальным и субгоризонтальным фрагментами обсадной колонны боевой скважины.

\section{Результаты}

Построена карта аномального магнитного поля $\Delta T_{\mathrm{a}}=$ Tизмі $-T \mathrm{var}_{\mathrm{i}}$, которое получено путем вычитания значений модулей полного вектора геомагнитного поля на магнитовариационной станции $\operatorname{Tvar}_{\mathrm{i}}$ и в точке магнитной съемки Тизмі, измеренных одновременно (рис. 4).

Проведена качественная интерпретация аномального магнитного поля. В первую очередь, выделим магнитные аномалии, вызванные техногенными объектами, расположенными на поверхности:

- слабые аномалии от железной бочки, железного листа и проволоки, обнаруженных на юго-западе площадки (объекты $d, e, f$, рис. 4 );

- положительную изометричную аномалию с амплитудой в 800 нТл и диаметром до 25 м, создаваемую шиной от карьерного грузовика БЕЛАЗ, лежащей на северо-восточном подножье саркофага (объект $c$, рис. 4);

- вытянутые отрицательные аномалии по краям участка магнитной съемки, источником которых является забор из металлических столбов и колючей проволоки (показано контуром бирюзового цвета, рис. 4);

- интенсивную отрицательную аномалию, сформированную на южном крае площадки под совместным действием забора и двух труб, проложенных под насыпной дорогой на глубине примерно 1 м для переброски склоновых стоков, названную южной аномалией (объект $b$, рис. 4 ).

Особо выделяется интенсивная изометричная аномалия в центре саркофага. Она имеет положительный характер с амплитудой более 8000 нТл. В центральной части аномалии находится столб-репер, установленный над устьем боевой скважины с предположительной длиной около 4 м (рис. 2, c). Детализация центральной аномалии по профилю № 1 (рис. 3) показала, что на флангах аномалии: на северном - в интервале профиля от 8 до 64 м, на южном - в интервале от 134 до 170 м, наблюдается понижение модуля магнитной индукции с амплитудой 131 и 101 нТл до достижения отрицательных значений -114 и -55 нТл соответственно (рис. 5). В интервале от 77 до 121 м профиля аномальные значения магнитного поля выражены в виде резкого положительного пика с амплитудой 7700 нТл, который на 101-ом метре профиля, как раз у столба-репера, резко сменяется на узкий отрицательный пик с амплитудой 2400 нТл и шириной по его основанию всего в 4 м (в интервале 99-103 м профиля). Ширина центральной магнитной аномалии составляет 46 м, что совпадает с данными площадной съемки.

Детализационный профиль № 2 пересекает в поперечном направлении две трубы длиной около 30 м, проложенные рядом под дорожной насыпью на глубине примерно 1 м, и забор (рис. 3). Толщина металла труб равна 0,8 см, диаметр труб - $102 \mathrm{cm:} \mathrm{согласно}$ ГОСТ погонная масса такой трубы составляет 201 кг/м. Южная магнитная аномалия, формируемая под совместным действием забора и этих двух железных труб определенной массы, геометрии и локализации, имеет форму «выраженный максимум с сопутствующими минимумами». При приближении с флангов на 10 м и ближе к трубам (и забору) наблюдается симметричное резкое снижение модуля магнитной индукции приблизительно на 400 нТл: от 
примерно -50 до -450 нТл (рис. 5). Магнитная аномалия выражена в виде двух узких высокоамплитудных пиков: первый положительный с амплитудой

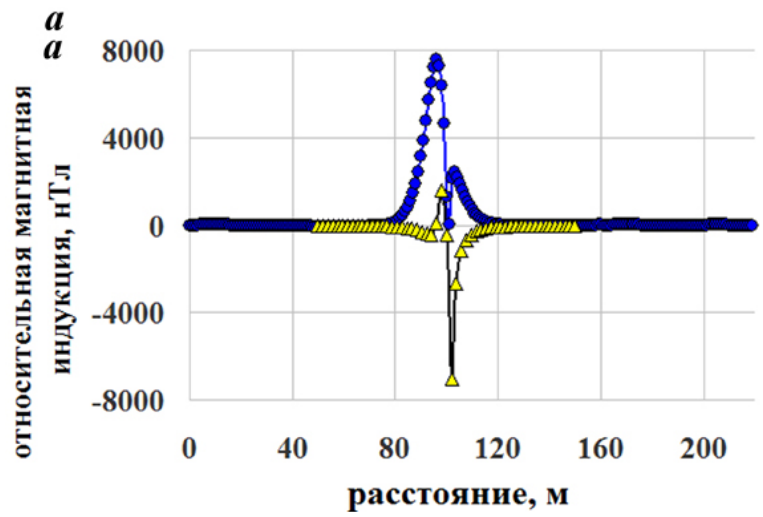

2050 нТл сменяется отрицательным пиком с амплитудой 6650 нТл. Поперечная ширина аномалии составляет всего $15,5 \mathrm{M}$.

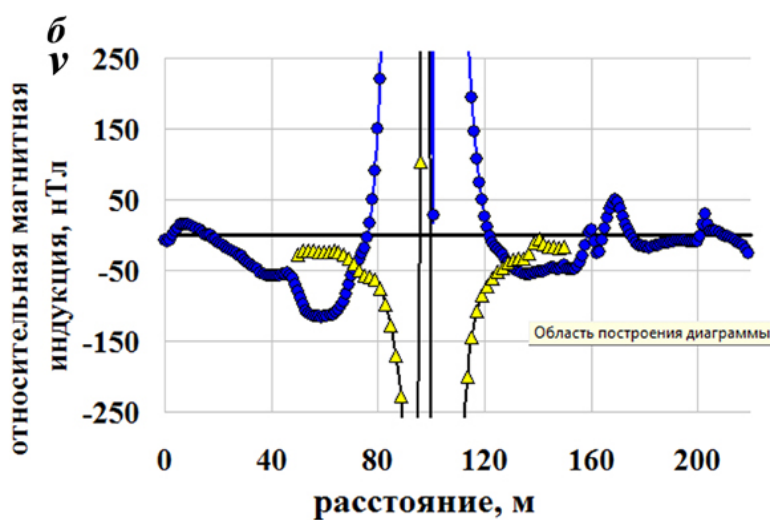

Рис. 5. Графики магнитных аномалий: центральной - по данным детализационного профиля № 1 (синие кружки), южной - по данным детализачионного профиля № 2 (желтые треугольники) в мелком (а) и крупном (б) масштабах

Fig. 5. Small-scale (a) and large-scale (b) diagrams of the central geomagnetic anomaly by the data of the profile no. 1 (blue mark), of the southern geomagnetic anomaly by the data of the profile no. 2 (yellow mark)

\section{Обсуждение}

По данным детализационного профиля № 2 общая амплитуда южной аномалии составляет 8700 нТл, а ее ширина - 15,5 м. По интенсивности южная и центральная аномалии сравнимы между собой. Заметим, что, если бы источником центральной аномалии был только столб-репер, она была бы не шире южной аномалии, сформированной под совместным влиянием таких же столбов - составляющих забора и двух крупных субгоризонтально расположенных труб диаметром 1 м. Но ширина центральной аномалии, равная 46 м, в 3 раза больше ширины южной аномалии. Кроме того, участки понижения магнитного поля на флангах центральной аномалии также существенно шире (58 м на северном фланге и 37 м на южном фланге) подобных участков у южной аномалии с шириной 10-14 м. Из этого можно заключить, что центральную магнитную аномалию формирует не только столб-репер, но и погребенные на значительно большей глубине, чем трубы южной аномалии, крупные железные объекты, по нашему мнению, несомненно, фрагменты обсадной колонны боевой скважины.

Отметим, что изометричная форма центральной аномалии дала нам повод усомниться в наличии под насыпью субгоризонтального фрагмента обсадной колонны, вылетевшего и лежавшего около устья боевой скважины [17], поскольку он вполне мог быть перемещен или удален до создания насыпи (саркофага) в 1992 г. Для верификации его наличия на месте была применена энергетическая фильтрация данных в программе «КОСКАД 3D» [19]. Путем выделения наиболее энергоемкой составляющей суммарного магнитного поля с последовательным ее вычитанием из исходного поля удалось разделить центральную аномалию на три составляющие (рис. 6):

a) наиболее энергоемкая составляющая суммарного магнитного поля, формирующая положительную изометричную аномалию (до 2200 нТл); b) умеренно-энергоемкая составляющая суммарного магнитного поля, формирующая изометричную аномалию с положительными значениями в центре (до 1500 нТл) и отрицательными на ее периферии (до -400 нТл) с дальнейшим обратным пологим повышением значений (до 0 нТл);

c) слабо-энергоемкая составляющая суммарного магнитного поля, формирующая субширотную линейную аномалию с двумя участками положительных значений, по периферии которых наблюдаются по два локальных участка отрицательных значений.

Известно, что источники различной геометрической формы образуют магнитные аномалии определенной морфологии [21]. Вместе с тем, наоборот, по форме магнитной аномалии можно судить об ее источнике. Мы попытались увязать составляющие центральной магнитной аномалии с железными фрагментами конструкции боевой скважины, известными по архивным документам, и даже сверх того - предположить произошедшие с ними изменения под воздействием взрыва. Известно, что при взрыве верхние 12 м обсадной колонны оторвало и выбросило на поверхность Земли (рис. 2) [17]. А нижняя часть (26 м) осталась в стволе боевой скважины: поднявшись под действием ударной волны со всем массивом горных пород вверх, по-видимому, опустилась обратно практически на исходное место, как и шестиметровое шахтное направление, оставшееся под землей. Мощность насыпи над устьем боевой скважины, исходя из полевых наблюдений, показаний GPS-навигатора и спутниковых данных, оценена примерно в 15 м. С учетом мощности насыпи и длины вытолкнутого из ствола фрагмента, верхняя кромка вертикального фрагмента обсадной колонны находится примерно на глубине $15 \mathrm{~m}+12 \mathrm{~m}=27 \mathrm{м}$, а интервал глубин его расположения в стволе боевой скважины составляет 27-53 м. 
Наиболее энергоемкая составляющая суммарного магнитного поля представляет собой изометричную положительную магнитную аномалию, плавно нисходящую от центра к периферии (рис. 6, a), и именно подобную аномалию формирует погруженное вертикальное цилиндрическое тело [21]. Следовательно, с большой долей уверенности эту составляющую можно соотнести с вертикальным фрагментом обсадной колонны длиной 26 м, оставшимся в стволе боевой скважины примерно на глубине 27-53 м.

Слабо-энергоемкая составляющая суммарного магнитного поля имеет характерную форму аномалии для вытянутого горизонтального пласта (рис. 6, c), что указывает на присутствие 12-метрового субгори- зонтального фрагмента обсадной колонны, погребенного под насыпью (рис. 2). Наличие на месте этого фрагмента подтверждает совпадение направления вытянутой стороны магнитной аномалии с априорными данными - с северо-западо-западной ориентацией этого фрагмента, установленной нами по фото 1990 г. (рис. 6, c) [17].

Умеренно-энергоемкую составляющую суммарного магнитного поля, ярко проявленную в виде контрастной изометричной аномалии с выраженной положительной центральной частью и сопутствующим периферийным минимумом (рис. $6, b$ ), трудно сходу соотнести с каким-либо фрагментом боевой скважины, исходя из априорных данных.
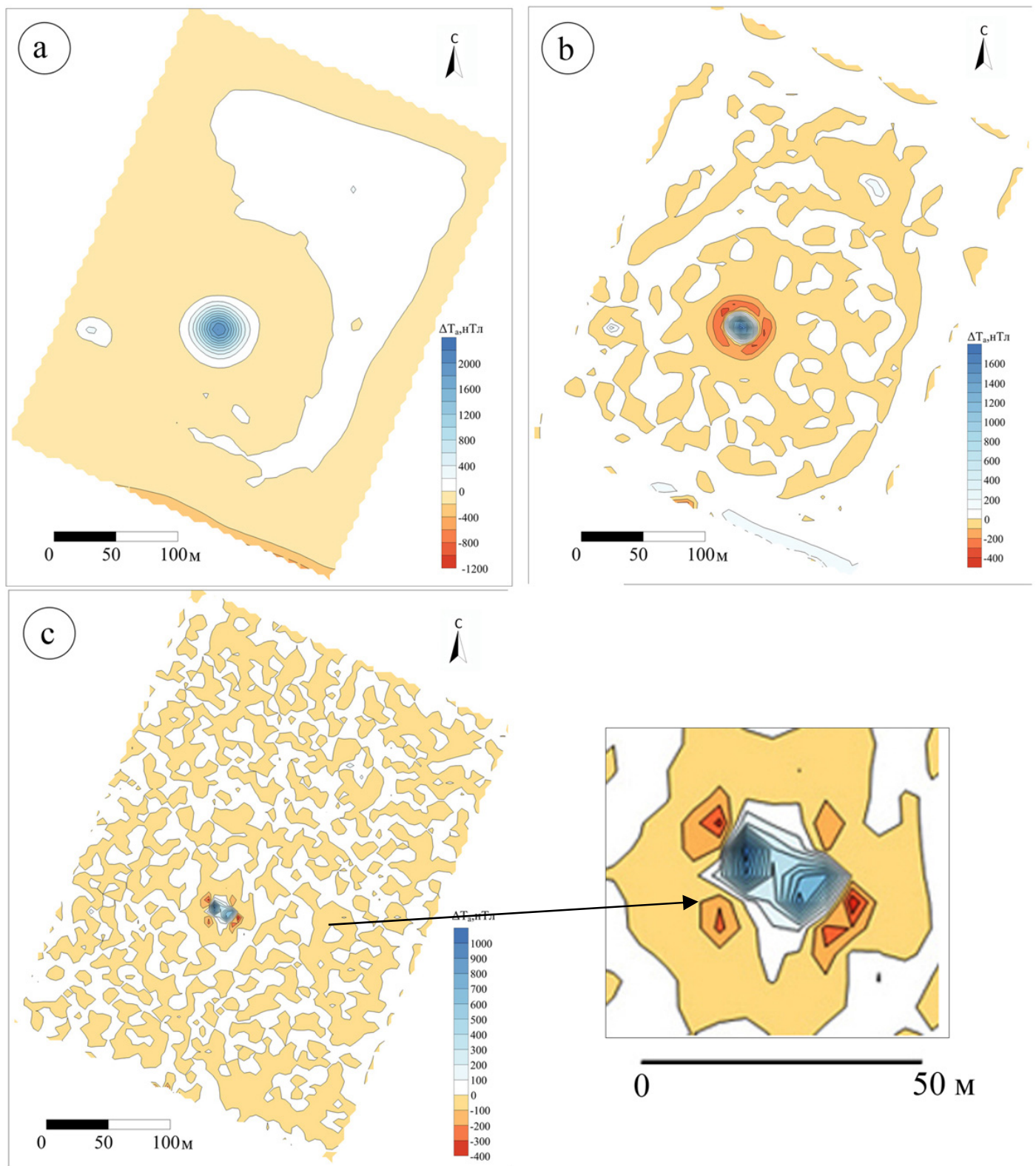

Pис. 6. Энергетическая фильтрачия магнитного поля площчадки ПЯВ «Кристалл»: a) наиболее энергоемкая; b) умеренно-энергоемкая; с) слабо-энергоемкая составляющие суммарного магнитного поля и его увеличенный вид (справа)

Fig. 6. Energetic filtration of geomagnetic field data of the site of PUNE «Crystal»: a) maximally energy capacious component of the geomagnetic field; b) moderate energy capacious component of the geomagnetic field; c) low energy capacious component of the geomagnetic field and its large-scale part (on the right) 
Известно, что массивные кубы, ограниченные снизу цилиндры, а в идеале - шарообразные объекты формируют магнитные аномалии подобной морфологии [21]. Можно предположить, что основным источником умеренно-энергоемкой составляющей суммарного магнитного поля является массивный ограниченный снизу объект, по форме близкой к изометричной. И тут вспомним «шахтное направление» - укрепительную конструкцию в верхней части ствола боевой скважины (под ее устьем) из трубы длиной 6 м и диаметром 1,42 м, которая монтировалась в боковые рыхлые породы, по-видимому, с бетонированием и использованием железной арматуры, и поэтому являла собой более широкий и массивный объект, чем просто вертикальный цилиндр из трубы.

При взрыве ударная волна поднимает массив горных пород в виде купола, где каждая частица массива двигается синхронно с другими, как при подъеме, так и при его обратном падении (рис. 7) [22]. На кинокадре примерно в 20 м над куполом взрыва ПЯВ «Кристалл» зафиксированы удлиненные объекты длиной 6-10 м при ширине основания купола в 200 м [17]. На основании форм и четких контуров этих объектов предполагаем, что это - металлические трубы. Отделение объектов от общего массива вещества купола можно объяснить только их дополнительным ускорением, по-видимому, под действием газов, прорвавшихся с большой силой из недр на ранних стадиях взрыва. Известно, что проектное просачивание газов предполагает их более спокойное истечение на поздней стадии ПЯВ [22]. Таким образом, этот кинокадр становится доказательством, что сильный поток газов из недр вырывался на ранней стадии взрыва.

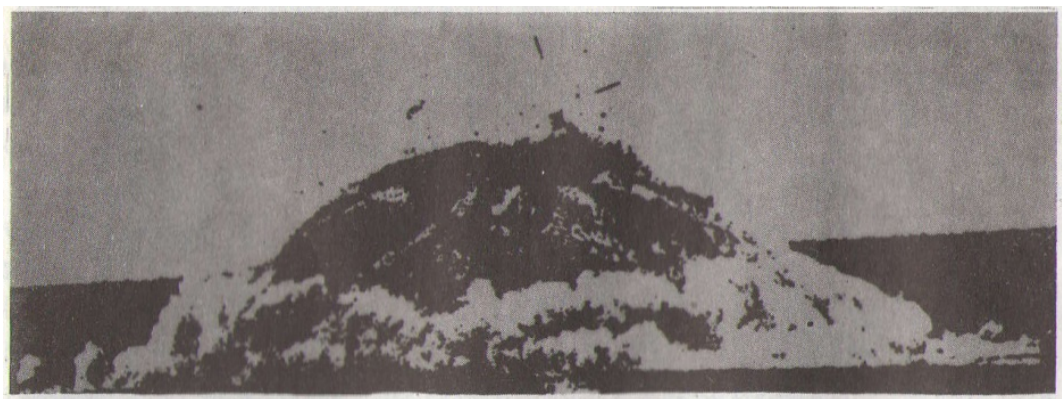

Рис. 7. Кадр из киносъемки ПЯВ «Кристалл» (примерно 4,5 с после начала взрыва, купол уже падает) [17]

Fig. 7. Film frame of the PUNE «Crystal» (about 4,5 sec after explosion starting, the cupola of explosion being fall) [17]

Впрочем, на мощный поток газов в момент взрыва указывает выталкивание практически $1 / 3$ обсадной колонны (12 м) из ствола скважины на поверхность (рис. 2). При этом шахтное направление оставалось в стволе. Следовательно, поток газа проходил по узкому пространству между обсадной колонной и шахтным направлением и действовал не только на разрыв и выталкивание фрагмента обсадной колонны, но и в боковом направлении, расширяя проход, в том числе деформируя (скорее всего, раздувая) трубу шахтного направления, что, по-видимому, сделало шахтное направление более изометричным. И тогда умеренноэнергоемкую составляющую суммарного магнитного поля, ярко проявленную в виде контрастной изометричной аномалии с выраженной положительной центральной частью и сопутствующим периферийным минимумом, можно соотнести с шахтным направлением с новой деформированной поствзрывной формой, залегающим в верхней части ствола боевой скважины примерно на глубине 18-24 м.

Таким образом, общие рассуждения и анализ априорных данных позволили с большой долей вероятности соотнести непонятную вначале умеренноэнергоемкую составляющую с реальным железным объектом и даже качественно оценить его деформацию при взрыве.

Пространственное совмещение трех составляющих магнитного поля, выделенных последовательной энергетической фильтрацией, показало практическое совмещение центров двух изометричных аномалий, что указывает на нахождение вертикального фрагмента обсадной колонны и шахтного направления в стволе боевой скважины (рис. 8). В пределах контуров этих магнитных аномалий располагается билатеральная аномалия от субгоризонтального фрагмента, что подтверждает его расположение рядом с устьем боевой скважины. Следовательно, можем говорить об отсутствии какого-либо значимого пространственного разноса фрагментов конструкции боевой скважины относительно друг друга.

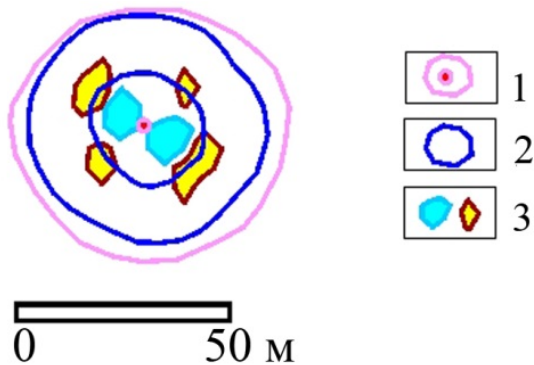

Рис. 8. Пространственно-совмещенные контуры наиболее энергоемкой (1), умеренно- (2) и слабо-энергоемкой составляющих (3) магнитного поля центтральной аномалии объекта «Кристалл»

Fig. 8. Contours of spatial-coinciding of the maximal (1), moderate (2) and low (3) energy capacious components of the geomagnetic field of the central anomaly of the «Crystal» object 
Необходимо подчеркнуть, что соотнесение составляющих суммарного магнитного поля с конкретным железным фрагментом конструкции боевой скважины указывает только на доминирующую роль этого фрагмента в формировании данной составляющей, но не исключает влияние остальных, в том числе неучтенных локальных железных объектов, расположенных в пределах центральной магнитной аномалии. Отметим, при энергетической фильтрации вклад столба-репера в суммарную магнитную аномалию не удалось выделить, возможно, в силу его чрезвычайной локальности, поскольку при полевых замерах он проявлялся в виде очень узкого и интенсивного отрицательного пика: с шириной по основанию всего в 4 м, с амплитудой 2400 нТл (рис. 5).

C применением программы PRIZMA [20] рассчитаны численные модели магнитных аномалий, формируемых фрагментами обсадной колонны боевой скважины, основные физические параметры и размеры которых известны по архивным и опубликованным данным [17], а их приблизительное положение определено нами на основе измеренных и априорных данных. Ниже рассмотрим эти модели:

1. Модель магнитного поля от фрагмента обсадной колонны, оставшегося в стволе боевой скважины на глубине 27-53 м в вертикальном положении длиной (высотой) 26 м, с эффективной намагниченностью $\mathrm{J}_{э \phi}=40 \mathrm{~A} / \mathrm{м}$ (рис. 9, $a$ ). Вектор эффективной намагниченности был принят вертикальным. В итоге получена слабая положительная и изометричная в плане магнитная аномалия с максимальной амплитудой 7,5 нТл, которая по форме и по размерам весьма похожа на экспериментальные данные - на наиболее энергоемкую составляющую центральной магнитной аномалии с амплитудой до 2000 нТл, соотнесенную с вертикальным 26-метровым фрагментом боевой скважины (рис. 6, a), но по интенсивности значительно - почти в 250 раз - слабее. Значительное расхождение между расчетными и экспериментальными данными, возможно, обусловлено тем, что:

- реальная масса вертикального фрагмента значительно выше массы, заложенной в расчеты, возможно, из-за наличия неучтенных объектов внутри или рядом;

- вклад шахтного направления в наиболее энергоемкую составляющую измеренного магнитного поля более значителен, чем мы полагали (как уже отмечали, что соотнесение составляющих суммарного магнитного поля с конкретным железным фрагментом конструкции боевой скважины указывает только на доминирующую роль этого фрагмента в формировании данной составляющей, но не исключает влияние остальных);

- существуют еще другие упущенные нами при моделировании обстоятельства.

Расхождение между моделью и измеренными данными в части аномалии от вертикального фрагмента обсадной колонны может быть снижено путем подбора расчетных вариантов.
2. Модель магнитного поля от субгоризонтального фрагмента длиной 12 м, расположенного на глубине 15 м в субширотном направлении, с эффективной намагниченностью $\mathrm{J}_{\text {эф}}=40 \mathrm{~A} / \mathrm{m}$ (рис. 9, b1). Дополнительно был рассмотрен вариант модели при расположении фрагмента трубы на глубине 24 м (рис. 9, b2). Вектор эффективной намагниченности был принят также вертикальным. В результате получена модель магнитной аномалии с амплитудой до 6500 нТл, где в центральной части выделяется билатеральная субширотная аномалия с положительными, по периферии - с отрицательными значениями (рис. 9, b1). Численная модель как по форме, так и по размеру походит на слабо-энергоемкую составляющую измеренного магнитного поля, соотнесенную нами с погребенным субгоризонтальным фрагментом обсадной колонны (рис. 6, c), также разница интенсивности расчетной и экспериментальной аномалий невысокая - примерно в 6,5 раз расчетная получилась выше. При погружении железного фрагмента на глубину до 24 м расчетная магнитная аномалия становится немного шире, более изометричной, с более плавными переходами, ее интенсивность снижается (до 4500 нТл), при этом в целом билатеральность аномалии сохраняется (рис. 9, b2). Видно, что интенсивность второго варианта численной модели получилась ближе к измеренным данным магнитной аномалии.

Таким образом, численное моделирование подтвердило верность соотнесения слабо-энергоемкой составляющей центральной магнитной аномалии именно с субгоризонтальным фрагментом обсадной колонны. Следующим шагом стало суммирование моделей магнитного поля а и $\mathrm{b} 2$, создаваемого источниками - вертикальным 26-метровым и субгоризонтальным 12-метровым фрагментами обсадной колонны (рис. 9, c). Суммарная аномалия по форме и амплитуде (до 4000 нТл) оказалась довольно близка к экспериментально измеренной центральной аномалии (аномалия 1, рис. 4). На карте разности измеренного магнитного поля и суммарного расчетного поля (рис. 9, d) в центральной части изометричной положительной магнитной аномалии отобразилась очень локальная, но весьма контрастная отрицательная аномалия с оперяющими положительными значениями, которая, по-видимому, соответствует магнитной аномалии от поверхностного столба-репера.

Итак, численные модели и последовательная энергетическая фильтрация показали, что крупная изометричная центральная магнитная аномалия формируется под действием нескольких железных фрагментов, в том числе субширотно-ориентированного субгоризонтального фрагмента обсадной колонны, погребенного под саркофагом (рис. 10). Дальнейшее численное моделирование позволит уточнить глубину расположения вертикального 26-метрового фрагмента обсадной колонны в стволе боевой скважины и, вероятно, другие параметры объекта, также проверить наше предположение о расположении шахтного 
направления, состоявшего из шестиметровой трубы, деформированной при взрыве, в диапазоне глубин 18-24 м, путем подбора оптимальных моделей.

Помимо рассмотренной центральной магнитной аномалии (№ 1, рис. 4) на саркофаге существует множество локальных магнитных аномалий, погребенные источники которых неизвестны. Наиболее крупные и интенсивные из этих аномалий пронумерованы на карте (рис. 4, № 2-8). Сделано предположение, что эти магнитные аномалии могут быть вызваны остатками обсадных труб буровых скважин и технологических труб. Перед проведением ПЯВ в 1973-1974 гг. для ис- следовательских целей на площадке «Кристалл» были пробурены три скважины глубиной 68,7; 74,5 и 153 м, обсаженные только в верхней части - в интервале 0-18 м. Чуть раньше здесь были пробурены еще две геологические скважины глубиной 11-12 м. То есть существовало пять обычных буровых скважин, исходное местоположение которых известно (рис. 11). При строительстве боевой скважины для подачи цемента для забивки ствола и заколонного пространства использовались металлические трубы, и, судя по кинокадрам, при взрыве первыми, по-видимому, были выброшены из земли именно эти трубы (рис. 7) [17].

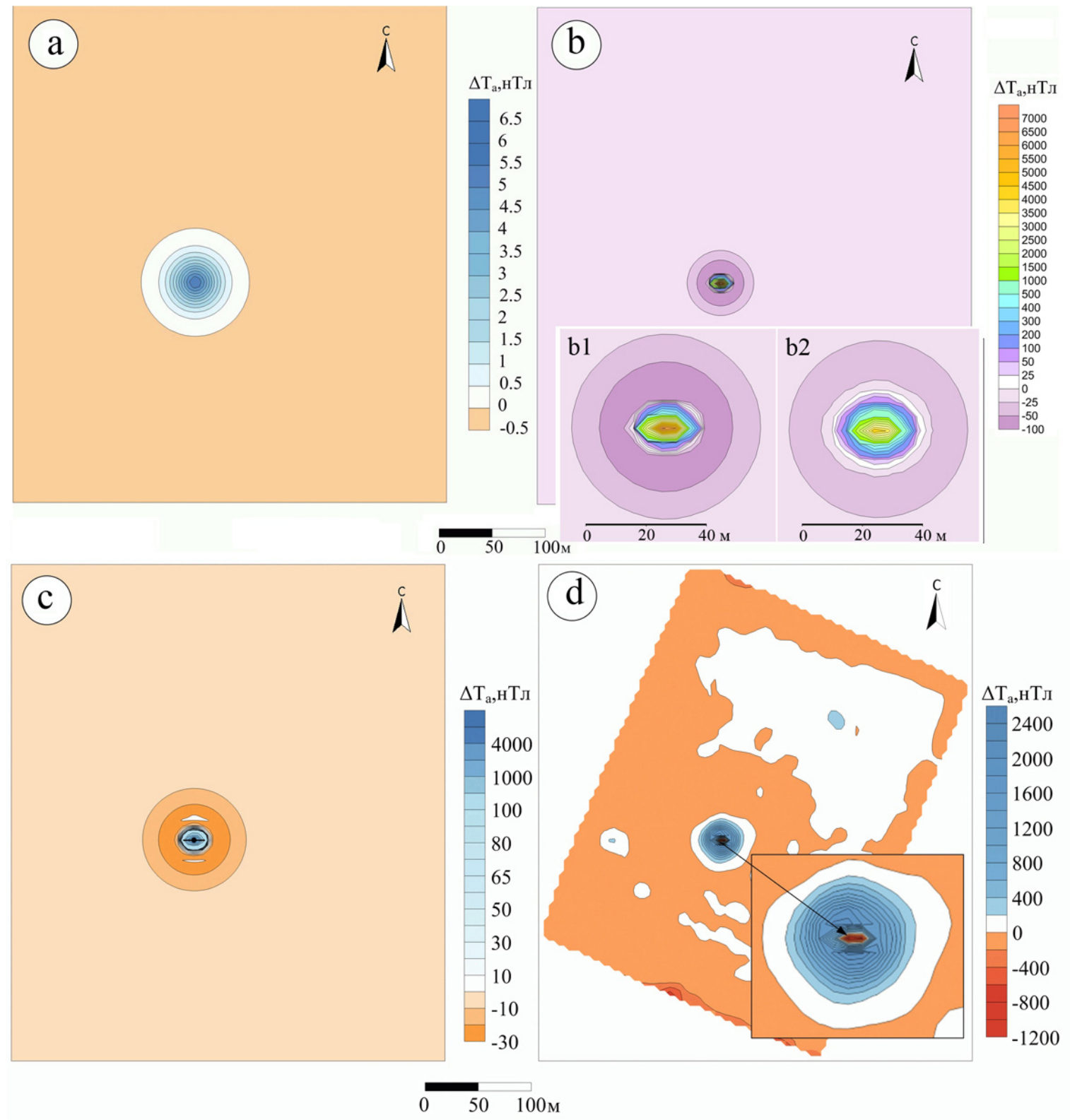

Pис. 9. Расчетные магнитные аномалии: а) для вертикального 26-метрового фрагмента обсадной колонны; b) для субгоризонтального фрагмента обсадной колонны: при залегании на глубине 15 м (b1), при его погружении на глубину 24 м (b2); c) суммарная магнитная аномалия двух моделей - a и b2; d) разность измеренного магнитного поля на площадке ПЯВ «Кристалл» и суммарной магнитной аномалии

Fig. 9. Computing models of magnetic anomalies: a) for vertical $26 \mathrm{~m}$ long casing fragment; b) for sub-horizontal $12 \mathrm{~m}$ long casing fragment: in $15 \mathrm{~m}$ depth (b1), in $24 \mathrm{~m}$ depth (b2); c) summary anomaly of two models $-a$ and b2; d) difference between experimental geomagnetic field data and summary anomaly 

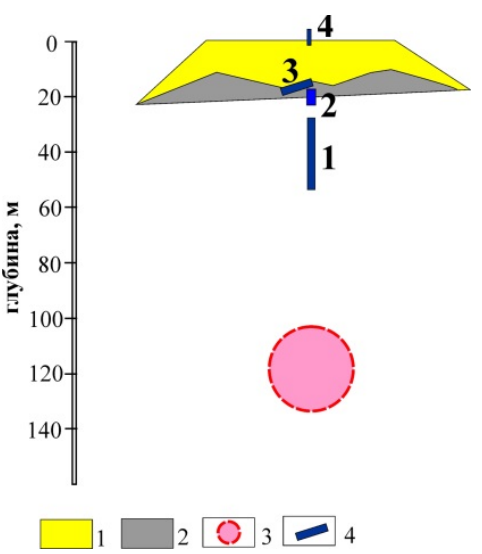

Рис. 10. Схема расположения железных фрагментов конструкиии боевой скважины ПЯВ «Кристалл» в разрезе. Условные обозначения: 1 - саркофаг насыпь из обломков пустой породы (известняков и доломитов); 2 - навал, сформировавшийся при взрыве; 3 - иентр взрыва; 4 - источники магнитного поля: 1 и 3 - фрагменты обсадной колонны, 2 - труба шахтного направления, 4 столб-репер над устьем боевой скважинь

Fig. 10. Situation scheme (vertical cut) of iron fragments of the PUNE «Crystal» emplacement hole. Legend: 1 the mound, constructed from rock debris (dolomites and limestone); 2 - the hill, formed due to the PUNE "Crystal»; 3 - PUNE centre; 4 - iron sources of magnetic anomalies: 1 and 3 -casing fragments, 2 cellar pit, 4 - benchmark of the emplacement hole

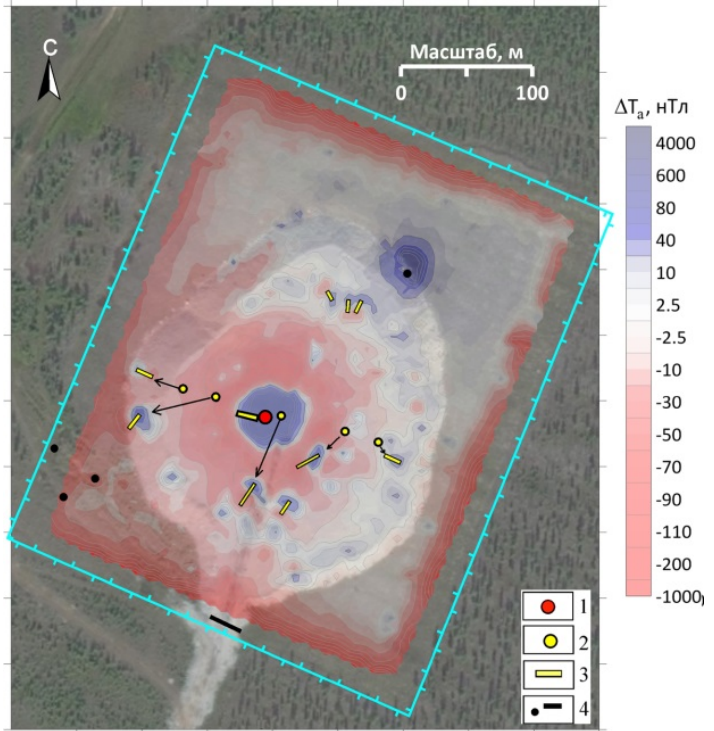

Рис. 11. Положение скважин до взрыва и предполагае мое перемещение обсадных труб этих скважин при взрыве. Условные обозначения: 1 - боевая скважина; 2 - скважины (до взрыва); 3 - обсадные трубы (слева у устья боевой скважсины фрагмент ее обсадной колонны); 4 - поверхностные железные объекты (см. рис. 3).

Fig. 11. Location of prospecting wells in the site before PUNE «Crystal» and supposed moving of their casing under the action of explosion. Legend: $1-\mathrm{em}-$ placement hole; 2 - prospecting wells (before explosion); 3 - casing fragments of wells (near the emplacement hole - the sub-horizontal fragment of its casing); 4 -iron objects on the land surface
Сделана попытка увязать локальные магнитные аномалии с буровыми скважинами: на рис. 11 показано положение скважин до взрыва (желтыми кружками) и возможное положение их обсадных труб после взрыва по результатам магнитной съемки. Хаотичное расположение объектов может быть объяснено тем, что ядерный взрыв - стадийный процесс, что влечёт в некотором смысле необъяснимое теорией обычного взрыва расположение поднятого материала.

\section{Выводы}

Результаты впервые проведенных исследований магнитного поля на площадке боевой скважины ПЯВ «Кристалл» позволяют сделать следующие выводы:

1. На площадке ПЯВ «Кристалл» существует ряд магнитных аномалий разной интенсивности и размеров, среди которых самой широкой и наиболее интенсивной является центральная изометричная в плане аномалия диаметром 46 м и амплитудой 8000 нТл, расположенная над устьем боевой скважины.

2. Детализация измерений и сравнение с магнитной аномалией, сформированной приповерхностными железными объектами, показало, что центральная аномалия формируется не только столбом-репером, установленным на поверхности саркофага, но и крупными погребенными железными объектами фрагментами конструкции боевой скважины.

3. Последовательная энергетическая фильтрация измеренных данных магнитного поля и численное моделирование подтвердили наличие на месте двенадцатиметрового фрагмента обсадной колонны, вытолкнутого при взрыве, субгоризонтально залегающего под насыпью около устья боевой скважины на глубине примерно 15 м, ориентированного в субширотном (северо-западо-западном) направлении;

4. Три составляющие центральной магнитной аномалии, выделенные последовательной энергетической фильтрацией, соотнесены с их основными источниками - погребенными фрагментами конструкции боевой скважины:

- слабо-энергоемкая составляющая суммарного магнитного поля билатеральной морфологии соотнесена с субгоризонтальным двенадцатиметровым фрагментом обсадной колонны боевой скважины;

- основным источником умеренно-энергоемкой составляющей суммарного магнитного поля, представленной в виде контрастной изометричной аномалии с выраженной положительной центральной частью и сопутствующим периферийным минимумом, является предположительно деформированное (раздутое) газовым потоком, вырвавшимся из недр на ранней стадии подземного ядерного взрыва, и ставшее более изометричным массивное шахтное направление, состоящее из шестиметровой трубы с исходным диаметром 1,42 м и крепежной арматуры; 
- наиболее энергоемкая составляющая суммарного магнитного поля в виде изометричной положительной магнитной аномалии формируется вертикальным 26-метровым фрагментом обсадной колонны, расположенным в стволе боевой скважины.

5. Опираясь на априорные архивные данные и результаты энергетической фильтрации, проведено численное моделирование двух фрагментов обсадной колонны боевой скважины, которое показало аддитивный характер центральной магнитной аномалии, формируемой тремя погребенными фрагментами конструкции боевой скважины: одним субгоризонтальным и двумя - в стволе боевой скважины. Кроме того, присутствует локальный вклад столба-репера, установленного на поверхности насыпи (саркофага).

6. Ранний выход мощного потока газа через околоствольное пространство боевой скважины смог вытолкнуть не только верхний двенадцатиметровый фрагмент обсадной колонны на поверхность, но мог и сдвинуть оставшийся фрагмент вверх относительно боковых пород. А обрушение полости взрыва, происходящее обычно через много часов, сутки после взрыва, наоборот, могло привести к углублению фрагмента обсадной колонны вместе

\section{СПИСОК ЛИТЕРАТУРЫ}

1. Мирные ядерные взрывы: обеспечение общей и радиационной безопасности при их проведении / под рук. В.А. Логачева. М.: ИздАТ, 2001. $-512 \mathrm{c}$.

2. Поисковая интернет-платформа баз данных публикаций в научных журналах и патентов. URL: http://apps. webofknowledge.com (дата обращения 05.03.2020).

3. The geoelectric structure at the site of «Crystal» underground nuclear explosion (Western Yakutia) from TEM data / N.O. Kozhevnikov, E.Yu. Antonov, S.Yu. Artamonova, A.E. Plotnikov // Russian Geology and Geophysics. - 2012. V. 53. - Iss. 2. - P. 185-193. URL: http://www.ipgg.sbras.ru/ru/ science/publications/publ-the-geoelectric-structure-at-the-site-ofcrystal-047075 (дата обращения 25.10.2020).

4. Artamonova S.Yu., Kozhevnikov N.O., Antonov E.Yu. Permafrost and ground water settings at the site of «Kraton-3» peaceful underground nuclear explosion (Yakutia), from TEM data // Russian Geology and Geophysics. - 2013. - V. 54. - Iss. 5. P. 555-565. URL: https://www.sciencedirect.com/science/article/ abs/pii/S106879711300076X (дата обращения 25.10.2020).

5. Directional location of buried objects using three-component magnetic borehole data demonstrated for the case of a drill string / S. Ehmann, C. Virgil, A. Hördt, M. Leven // Geophysical Journal International. - 2016. - V. 205. - Iss. 3. - P. 1916-1925. URL: https://academic.oup.com/gii/article/205/3/1916/658837 (дата обращения 25.10.2020).

6. Ayad A., Bakkali S. Analysis of the magnetic anomalies of buried archaeological ovens of Am Kerouach (Morocco) // International Journal of Geophysics. - 2018. - V. 2018. - ID 9741950. URL: https://www.hindawi.com/journals/ijge/2018/9741950/ (дата обращения 25.10.2020).

7. Archaeological prospections in the Roman vicus Belginum (Rhineland-Palatinate, Germany) / W-R. Teegen, R. Cordie, Ph. Over, S. Magdefessel, R. Retzlaff, J. Stoffels // E\&Q Quaternary Science Journal. - 2019. - V. 68. - Iss. 1. - P. 5-11. URL: https://egqsj.copernicus.org/articles/68/5/2019/ (дата обращения 25.10.2020).

8. Localized geomagnetic field anomalies in an underground gas storage / Z. Wang, B. Chen, J. Yuan, F. Yang, L. Jia, C. Wang // Physics of the Earth and planetary interiors. - 2018. - V. 283. - с окружающим массивом горных пород. При дальнейшем численном моделировании путем подбора оптимальных моделей можно будет уточнить глубину расположения как вертикального фрагмента обсадной колонны, так и шахтного направления боевой скважины и, возможно, другие параметры объектов.

7. Источником малоинтенсивных и локальных магнитных аномалий, предположительно, являются фрагменты обсадных труб исследовательских буровых скважин, существовавших до взрыва на площадке, и технических труб, использованных при обустройстве боевой скважины, хаотично перемещенных при взрыве.

Первичные данные наземной магнитной съемки площадки объекта ПЯВ «Кристалл» систематизированы в базу данных [23] и могут быть доступны каждому при обращении в ИГМ СО РАН к С.Ю. Артамоновой.

Работа выполнена при поддержке грантов РФФИ № 18-45-140020, РФФИ 19-05-00654A по государственному заданию ИГМ СО РАН и ИНГГ СО РАН, по государственному заказу № Ф.2019.473808 в рамках программы «Обеспечение экологической безопасности, рачионального природопользования и развитие лесного хозяйства РС (Я) на 2018-2022 годыl».

P. 92-97. URL: https://www.sciencedirect.com/science/ article/pii/ S0031920118300943?via\%3Dihub (дата обращения 25.10.2020).

9. Beggan C.D., Billingham L., Clarke E. Estimating external magnetic field differences at high geomagnetic latitudes from a single station // Geophysical prospecting. - 2018. - V. 66. - Iss. 6. P. 1227-1240. URL: https://doi.org/10.1111/1365-2478.12641 (дата обращения 25.10.2020).

10. Novikova P.N. Application of detailed magnetics in intensive industrial noise conditions // Practical and theoretical aspects of geological interpretation of gravitational, magnetic and electric fields. Springer Proceedings in the Earth and Environmental Sciences. - 2019. - P. 371-376. URL: https://link.springer. com/chapter/10.1007\%2F978-3-319-97670-9_43 (дата обращения 25.10.2020).

11. Residual radioactive contamination at the peaceful underground nuclear explosion sites «Craton-3» and «Crystal» in the Republic of Sakha (Yakutia) / A.D. Gedeonov, E.R. Petrov, V.G. Alexeev, I.N. Kuleshova, M.L. Savopulo, I.S. Burtsev, V.Yu. Shkroev, V.I. Arkhipov // J. Environ. Radioact. - 2002. - № 60. - P. 221-234. URL: $\quad$ https://www.sciencedirect.com/science/article/pii/ S0265931X01001059?via\%3Dihub (дата обращения 25.10.2020).

12. Radioecological studies at the Kraton-3 underground nuclear explosion site in1978-2007: a review / V. Ramzaev, A. Mishine, V. Golikov, T. Argunova, V. Ushnitski, A. Zhuravskaya, P. Sobakin, J. Brown, P. Strand // J. Environ. Radioact - 2009. V. 100. - Iss. 12. - P. 1092-1099. URL: https://www.sciencedirect.com/ science/ article/pii/S0265931X09000782?via\%3Dihub (дата обращения 25.10.2020)

13. Sobakin P.I., Ushnitskii V.E., Perk A.A. Radioecological situation in the region of Gorizont-4 underground nuclear explosion in Sakha Republic (Yakutia) // Radiochemistry. - 2019. - V. 61. Iss. 3. - P. 365-372. URL: https://link.springer.com/article/ 10.1134\%2FS1066362219030123 (дата обращения 25.10.2020).

14. Голубов Б.Н. Последствия техногенной дестабилизации недр Астраханского газоконденсатного месторождения в зоне подземных ядерных взрывов // Геоэкология. - 1994. - № 4. C. $25-42$.

15. Стогний В.В., Васильев С.П., Невольских С.Г. Изменения геофизических полей при подземных ядерных взрывах в Западной Якутии // Геофизические исследования в Якутии. Якутск: ЯГУ, 1998. - С. 153-165. 
16. Микуленко К.И., Чомчоев А.И., Готовцев С.П. Геологогеографические условия проведения и последствия подземных ядерных взрывов на территории Республика Саха (Якутия). Якутск: Изд-во ЯНЦ СО РАН, 2006. - 196 с

17. Бурцев И.С., Колодезникова Е.Н. Радиационная обстановка в алмазоносных районах Якутии (препринт). - Якутск: Изд-во ЯНЦ CO РАН, 1997. - 52 c. URL: https://yadi.sk/i/Kmp2f2scGdTLw (дата обращения 25.10.2020).

18. Геоэкологическая модель района мирного подземного ядерного взрыва «Кристалл» (Якутия) / С.Ю. Артамонова, Л.Г. Бондарева, Е.Ю. Антонов, Н.О. Кожевников // Геоэкология, инженерная геология, гидрогеология, геокриология. - 2012. № 2. - C. 143-158. URL: https://elibrary.ru/item.asp?id=17699401 (дата обращения 25.10.2020).

19. Coscad3D.ru. URL: www.coscad3d.ru (дата обращения 05.03.2020).

20. Долгаль А.С. Влияние сферичности Земли на результаты аэромагнитных измерений над платобазальтами (на примере
Норильского района) // Известия Томского политехнического университета. Инжиниринг георесурсов. - 2019. - V. 33. № 11. - P. 26-33. URL: https://www.elibrary.ru/item.asp?id= 41469499 (дата обращения 25.10.2020).

21. Магниторазведка: Справочник геофизика / под ред. Б.Е. Никитского, Ю.С. Глебовского. 2-е изд., перераб. и доп. - М.: Недра, 1990. - 470 с.

22. Адушкин В.В., Спивак А.А. Подземные взрывы. - М.: Наука, 2007. $-579 \mathrm{c}$

23. Свидетельство о государственной регистрации базы данных № 2020621125. - M.: Роспатент, 02.07.2020. URL: https://www1.fips.ru/registers-doc-view/fips_servlet?DB=DB\&

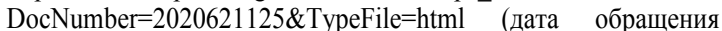
25.10.2020).

Поступила 18.11.2020 2.

\section{Информация об авторах}

Артамонова С.Ю., доктор геолого-минералогических наук, старший научный сотрудник Института геологии и минералогии им. В.С. Соболева СО РАН.

Шеин A.H., кандидат физико-математических наук, старший научный сотрудник Института нефтегазовой геологии и геофизики им. А.А. Трофимука СО РАН; ведущий научный сотрудник Научного центра изучения Арктики; доцент кафедры прикладной геологии и технологии геологической разведки Забайкальского государственного университета.

Потапов B.B., кандидат технических наук, старший научный сотрудник Института нефтегазовой геологии и геофизики СО РАН; доцент кафедры прикладной геологии и технологии геологической разведки Забайкальского государственного университета.

Кожсевников H.O., доктор геолого-минералогических наук, главный научный сотрудник Института нефтегазовой геологии и геофизики им. А.А. Трофимука СО РАН.

Новикова П.Н., кандидат геолого-минералогических наук, научный сотрудник Горного института УрО РАН. Уиницкий B.E., главный специалист Министерства экологии, природопользования и лесного хозяйства РС (Я). 
UDC $550.389+504.06$

\section{MAGNETIC ANOMALIES AT THE SITE OF THE PEACEFUL UNDERGROUND NUCLEAR EXPLOSION «CRYSTAL» (WESTERN YAKUTIA)}

\author{
Svetlana Yu. Artamonova1, \\ artam@igm.nsc.ru
}

\section{Aleksandr N. Shein $2,3,4$, SheinAN@ipgg.sbras.ru \\ Vladimir V. Potapov2,4, PotapovVV@ipgg.sbras.ru}

\author{
Nikolay 0. Kozhevnikov², \\ KozhevnikovNO@ipgg.sbras.ru
}

\author{
Polina N. Novikova ${ }^{5}$, \\ polinagfz@gmail.com
}

Vladislav E. Ushnitskiii,
ushnitski@mail.ru

1 V.S. Sobolev Institute of Geology and Mineralogy SB RAS,

3, Akademician Koptyug avenue, Novosibirsk, 630090, Russia.

2 Trofimuk Institute of Petroleum Geology and Geophysics SB RAS,

3, Akademician Koptyug avenue, Novosibirsk, 630090, Russia.

${ }^{3}$ Arctic Research Center of the Yamal-Nenets Autonomous District, 20, Respubliki street, Salekhard, 629008, Russia.

4 Transbaikal State University, 30, Aleksandro-Zavodskaya street, Chita, 672039, Russia.

5 Mining Institute UB RAS, 78a, Sibirskaya street, Perm, 614007, Russia.

${ }^{6}$ Ministry of Ecology, Nature management and Forestry of the RS (Ya), 31/1, Dzerzhinsky street, Yakutsk, 677000, Russia.

The relevance of the study is caused by the necessity to assess the current radiation and geo-ecological situation at the sites of peaceful underground nuclear explosions. In addition, this study will allow us to predict possible scenarios for development at such items located near settlements. The circumstantial research of the structure of the geotechnogenic system «center of an underground nuclear explosion - the host geological environment - the surface of the Earth» involves magnetic study. The land magnetic survey allow us to separate geoelectric anomalies caused by buried iron objects from other items that have a different nature.

The aim of the research is to detect and localize the buried iron objects on the site of the peaceful underground nuclear explosion "Crystal» based on the data of land magnetic survey.

Object. The area of the emplacement hole of the peaceful underground nuclear explosion «Crystal» was chosen for study. The capacity of the peaceful underground nuclear explosions "Crystal» was of 1,7 kt in TNT equivalent. It was made on October 2, 1974 at a depth of $98 \mathrm{~m}$ in frozen rocks at a distance of 6,7 $\mathrm{km}$ away from Udachny town (Western Yakutia). The debri mound (or sarcophagus) was built on the mouth of the emplacement hole in two steps - in 1992 and 2007. The diameter of the mound is $260 \mathrm{~m}$, its maximal height is $20 \mathrm{~m}$.

Methods. The magnetic survey was carried out on the profiles with a proton magnetometer MMPOS-1 with a reference frequency of $3 \mathrm{~s}$. Georeferencing of points was performed using the Garmin 64st GPS receiver. Variations of the Earth's natural magnetic field were registered by a GSM-19 quantum magnetometer with a frequency of $10 \mathrm{~s}$ in a forest area near «Crystal» sarcophagus. Software complexes of statistical and spectral-correlation analysis of geophysical data «KOSKAD 3D» (author A.A. Nikitin, A.V. Petrov, A.S. Aleksashin) and of numerical modelling PRIZMA (author A.S. Dolgal) are used for the data analysis.

Results. 5323 readings of magnetic field on the area 430×330 m around the emplacement hole of the peaceful underground nuclear explosion «Crystal» were taken and systemized. The anomalous magnetic field $\Delta T_{a}$ of the site of the peaceful underground nuclear explosion "Crystal» was mapped based on these data. The local magnetic anomalies formed by buried iron objects were revealed. The widest and most intense anomaly with a diameter of $46 \mathrm{~m}$ and an amplitude of up to $8000 \mathrm{nT}$ is located above the emplacement hole at the center of the sarcophagus. The sequential energy filtering of measured magnetic data allowed separating this magnetic anomaly into parts associated with different fragments of the emplacement hole casing. The results of modeling magnetic anomalies caused by the hole casing fragments are consistent with the measured magnetic data. So, the additive character of the magnetic anomaly is revealed. The other magnetic anomalies are presumably caused by casing pipes of research and technical wells that existed before the explosion at the site and were randomly removed by the explosion.

\section{Key words:}

Land geomagnetic survey, geoecological research, peaceful underground nuclear explosion, Yakutia.

The research was supported by the RFBR grants no. 18-45-140020, 19-05-00654A by the State tasks of V.S. Sobolev Institute of Geology and Mineralogy SB RAS and Trofimuk Institute of Petroleum Geology and Geophysics SB RAS, by the State Order no. Ф.2019.473808 within the program «Assurance of ecological safety, efficient use of natural resources and forestry development of Republic of Sakha (Yakutia) for 2018-2022». 


\section{REFERENCES}

1. Mirnye yadernye vzryvy: obespechenie obshchey $i$ radiatsionnoy bezopasnosti pri ikh provedenii [Peaceful nuclear explosion: common and radiation safety arrangements]. Chief V.A. Logachev. Moscow, IzdAT Publ., 2001. 512 p.

2. Poiskovaya internet-platforma baz dannykh publikatsiy $v$ nauchnykh zhurnalakh i patentov [The publisher-independent global citation database]. Available at: http://apps.webofknowledge.com (accessed 05 March 2020)

3. Kozhevnikov N.O., Antonov E.Yu., Artamonova S.Yu., Plotnikov A.E. The geoelectric structure at the site of «Crystal» underground nuclear explosion (Weastern Yakutia) from TEM data. Russian Geology and Geophysics, 2012, vol. 53, Iss. 2, pp. 185-193.

4. Artamonova S.Yu., Kozhevnikov N.O., Antonov E.Yu. Permafrost and ground water settings at the site of «Kraton-3» peaceful underground nuclear explosion (Yakutia), from TEM data. Russian Geology and Geophysics, 2013, vol. 54, Iss. 5, pp. 555-565.

5. Ehmann S., Virgil C., Hördt A., Leven M. Directional location of buried objects using three-component magnetic borehole data demonstrated for the case of a drill string. Geophysical Journal International, 2016, vol. 205, Iss. 3, pp. 1916-1925.

6. Ayad A., Bakkali S. Analysis of the magnetic anomalies of buried archaeological ovens of Am Kerouach (Morocco). International Journal of Geophysics, 2018, vol. 2018, ID 9741950.

7. Teegen W-R., Cordie R., Over Ph., Magdefessel S., Retzlaff R., Stoffels J. Archaeological prospections in the Roman vicus Belginum (Rhineland-Palatinate, Germany). E\&Q Quaternary Science Journal, 2019, vol. 68, Iss. 1, pp. 5-11.

8. Wang Z., Chen B., Yuan J., Yang F., Jia L., Wang C. Localized geomagnetic field anomalies in an underground gas storage. Physics of the Earth and planetary interiors, 2018, vol. 283, pp. 92-97.

9. Beggan C.D., Billingham L., Clarke E. Estimating external magnetic field differences at high geomagnetic latitudes from a single station. Geophysical prospecting, 2018, vol. 66, Iss. 6, pp. 1227-1240.

10. Novikova P.N. Application of detailed magnetics in intensive industrial noise conditions. Practical and theoretical aspects of geological interpretation of gravitational, magnetic and electric fields. Springer Proceedings in the Earth and Environmental Sciences, 2019. pp. 371-376

11. Gedeonov A.D., Petrov E.R., Alexeev V.G., Kuleshova I.N., Savopulo M.L, Burtsev I.S., Shkroev V.Yu., Arkhipov V.I. Residual radioactive contamination at the peaceful underground nuclear explosion sites «Craton-3» and «Crystal» in the Republic of Sakha (Yakutia). J. Environ. Radioact., 2002, no. 60, pp. 221-234.

12. Ramzaev V., Mishine A., Golikov V., Argunova T., Ushnitski V., Zhuravskaya A., Sobakin P., Brown J., Strand P. Radioecological studies at the Kraton-3 underground nuclear explosion site in 1978-2007: a review. J. Environ. Radioact., 2009, vol. 100, Iss. 12 pp. 1092-1099.
13. Sobakin P.I., Ushnitskii V.E., Perk A.A. Radioecological situation in the region of Gorizont-4 underground nuclear explosion in Sakha Republic (Yakutia). Radiochemistry, 2019, vol. 61, Iss. 3, pp. 365-372.

14. Golubov B.N. Posledstviya tekhnogennoy destabilizatsii nedr Astrakhanskogo gazokondensatnogo mestorozhdeniya $\mathrm{v}$ zone podzemnykh yadernykh vzryvov [Consequences of technogenic destabilization of the Astrakhan gas condensate field in the zone of underground nuclear explosions]. Geoekologiya, 1994, Iss. 4, pp. $25-42$.

15. Stogniy V.V., Vasiliev S.P., Nevolskikh S.G. Izmeneniya geofizicheskikh poley pri podzemnykh yadernykh vzryvakh v Zapadnoy Yakutii [Changes in geophysical fields after underground nuclear explosions in Western Yakutia]. Geofizicheskie issledovaniya $v$ Yakutii [Geophysical research in Yakutiya]. Yakutsk, YaGU Publ., 1998. pp. 153-165.

16. Mikulenko K.I., Chomchoev A.I., Gotovtsev S.P. Geologogeograficheskie usloviya provedeniya i posledstviya podzemnykh yadernykh vzryvov na territorii Respubliki Sakha (Yakutiya) [Geological and geographical conditions and consequences of underground nuclear explosions on the territory of the Republic of Sakha (Yakutia)]. Yakutsk, YaNC SO RAN Publ., 2006. 196 p.

17. Burtsev I.S., Kolodeznikova E.N. Radiatsionnaya obstanovka v almazonosnykh rayonakh Yakutii (preprint) [Radiation situation in the diamond-bearing regions of Yakutia (preprint)]. Yakutsk, YaNC SO RAN Publ., 1997. 52 p.

18. Artamonova S.Yu., Bondareva L.G., Antonov E.Yu., Kozhevnikov N.O. Geoecological model of «Crystall» peaceful underground nuclear explosion area (Yakutia). Environmental Geoscience, 2012, Iss. 2, pp. 143-158. In Rus.

19. Coscad3D.ru. Available at: www.coscad3d.ru (accessed 05 March 2020).

20. Dolgal A.S. Effect of Earth sphericity on the results of aeromagnetic measurements over platobasalts (on the example of Norilsk region). Bulletin of the Tomsk Polytechnic University. Geo assets engineering, 2019, vol. 33, no. 11, pp. 26-33. In Rus.

21. Magnitorazvedka: spravochnik geofizika [Magnetic survey: manual for geophysicists]. Eds. B.E. Nikitsky, Yu.S. Glebovsky. Moscow, Nedra Publ., 1990. 470 p.

22. Adushkin V.V., Spivak A.A. Podzemnye vzryvy [Underground explosions]. Moscow, Nauka Publ., 2007. 579 p.

23. Svidetelstvo o gosudarstvennoy registratsii bazy dannykh no. 2020621125 [The certificate on the state registration of a database No. 2020621125]. Moscow, Rospatent, July 2 2020. Available at: https://www1.fips.ru/registers-docview/fips_servlet?DB=DB\&DocNumber=2020621125\&TypeFile $=\mathrm{html}($ accessed 25 October 2020).

Received: 18 November 2020.

\section{Information about the authors}

Svetlana Yu. Artamonova, Dr. Sc., senior researcher, V.S. Sobolev Institute of Geology and Mineralogy SB RAS.

Aleksandr N. Shein, Cand. Sc., senior researcher, Trofimuk Institute of Petroleum Geology and Geophysics SB RAS; leading researcher, Arctic Research Center of the Yamal-Nenets Autonomous District; associate professor, Transbaikal State University.

Vladimir V. Potapov, Cand. Sc., senior researcher, Trofimuk Institute of Petroleum Geology and Geophysics SB RAS; associate professor, Transbaikal State University.

Nikolay O. Kozhevnikov, Dr. Sc., main research scientist, Trofimuk Institute of Petroleum Geology and Geophysics SB RAS.

Polina N. Novikova, Cand. Sc., researcher, Mining Institute UB RAS.

Vladislav E. Ushnitskii, chief specialist, Ministry of Ecology, Nature management and Forestry of the RS (Ya). 